\title{
Imaginarios postaxiales y resacralizaciones modernas
}

\section{Postaxial imaginary and modern resacralizations}

RELASO. Vol. 4 (2014) pp. 39-60. ISSN-e 2253-6469

DOI: http://dx.doi.org/10.17979/relaso.2014.4.1.1220
Josetxo Beriain

Universidad Pública de Navarra josetxo@unavarra.es

Recibido 1-07-2014

Aceptado 20-09-2014

\begin{abstract}
This paper takes into account the analysis of modern resacralization phenomena such as the nation and the person. Case studies as the French Revolution, the poswar Union of Europe movement, the Ceremony of Coronation of the Queen Elyzabeth II, the American civil religion, the ritual mobilizations that follow the attack against the WTC in the 9/11 and the 2008 American Presidential Election, show us the empirical support to explain the emergence of multiple postaxial sacred forms. Finally, there have been analysed two cases of modern societies where the modern resacralizations of the nation and the person are projected as symbolic cleavages.
\end{abstract}

Keywords: resacralization, nation, person, religion

\begin{abstract}
RESUMEN
El presente trabajo plantea el análisis de fenómenos de resacralización moderna como son la nación y la persona. El estudio de casos como la Revolución Francesa, el movimiento de unificación de la Europa de posguerra, la ceremonia de coronación de la reina Isabel II, la religion civil Americana, las movilizaciones rituales que siguen al ataque al WTC el 9/11 y las elecciones americanas de 2008, ofrecen el apoyo empírico para explicar la emergencia de formas sagradas multiples postaxiales. Finalmente, se analizan dos casos de sociedades modernas donde las resacralizaciones modernas de la nación y la persona se proyectan como ejes de conflicto simbólico.
\end{abstract}

Palabras clave: resacralización, nación, persona, religión

"Los antiguos dioses siguen vivos y han nacido otros modernos que los acompañan y compiten entre sí en una lucha sin fin" 
Recientemente han surgido estudios que muestran como la noción de "elección por Dios", que ha sido en primer lugar experimentada por los israelitas y formulada en los textos del Antiguo Testamento, ha sido adoptada por el movimiento nacionalista moderno1. Una parte de estos estudios examina las formas en que la idea de elección sirvió para justificar los objetivos y las acciones de una politica imperialista, mientras que otra parte de los estudios trata de explicar el sufrimiento proporcionando un estímulo a la emancipación política y a la liberación nacional. Ambas formas de elección pueden ser mezcladas con ideas de pureza racial y carácter único: los hombres que creyeron que eran portadores de una misión especial en los asuntos coloniales británicos del siglo XIX fueron muy conscientemente cristianos y blancos, así como lo fueron sus homólogos en los Países Bajos, en Alemania o en los Estados Unidos. Hay tres conceptos 2 que están a la base de las acciones de estos hombres: elementos religiosos, el nacionalismo secular y la noción de raza o de características raciales. Primero esta la idea de elección de un cierto pueblo, que conlleva e incorpora ingredientes políticos y sociales, así como religiosos. Segundo, el tema del revival o del renacimiento de la nación entera. Los pietistas y los metodistas introdujeron la metáfora del "renacimiento" (Awakening) una clase de regeneración colectiva- en el protestantismo del siglo XVIII y los nacionalistas del siglo XIX usaron la noción de revival para explicar y avanzar la idea de una nación cristiana, "a nation under God", como fue llamada en Estados Unidos. La tercera idea es la creencia en un nuevo Mesias que funge de líder espiritual (Moisés, Jesús, Mahoma, etc) y/o político. En 1914, incluso aquellos que recibieron una educación secular estaban socializados en historias bíblicas que imaginaron sus respectivos liderazgos politicos en términos bíblicos y con cualificaciones espirituales explicadas en el Viejo y en el Nuevo Testamento3. La comunidad nacional secular, religiosamente unida, se recreará creando conmemoraciones del pasado violento de la nación ("sacrificial Birth and Rebirth"). Como vemos, en todos estos ejemplos, "lo secular" y "lo religioso" se prestan conceptos, figuras y significados que ponen de manifiesto las inversiones ideológicas que se establecen entre ellos, incluso dentro de un mundo predominantemente secular.

Antes de comenzar a desvelar las formas complejas de lo religioso, conviene entender la génesis social de las formas de la vida religiosa4. Emile Durkheim en su último gran trabajo, Las formas elementales de la vida religiosa (1912), procede a explicar el hecho religioso a través de una minuciosa interpretación sobre la génesis social de la protodistinción directriz que diferencia entre las categorias epistemológico-analíticas de "lo sagrado" y "lo profano", a partir de las prácticas rituales que reproducen al colectivo social como tal. Para Durkheim, a diferencia de Weber que consideraba a las religiones como sistemas de creencias, esta protoclasificación no tiene su origen en creencias porque si así fuera no tendría un origen empírico en el ritual. De hecho, la razón para la realización performativa de tales prácticas es mantener el limite entre lo sagrado y lo profano, no tanto una creencia en seres sobrenaturales o en dioses misteriosos, como pretenden las concepciones convencionales de la religión. Lo sagrado no existe como una idea o creencia previa, solo a través del ritual viene a la existencia. La existencia de lo sagrado precede a la esencia-creencia en lo sagrado. Solo a través del acontecimiento apropiador del ritual emerge lo sagrado como algo diferenciado de lo profano. De ahí que Durkheim prefiera hablar más de "hechos religiosos y no de religión" 5 . Según él, "es la acción la que domina la vida religiosa por la sola razón de que la sociedad constituye su fuente originaria" (E. Durkheim, FE, 598/390). O en los términos de otro gran experto en 
Durkheim, Robert N. Bellah: "la religión es algo que tu haces...En la religión se trata de acción, en la fe se trata de confianza"6. Durkheim se concentra en el análisis de esas "formas más elementales de hechos religiosos", que él sitúa en el totemismo, para evitar precisamente la confusión metodológica entre lo sagrado y lo trascendente, término este último asociado al nuevo dualismo (el otro mundo/este mundo) que generarán las religiones universales que surgen en la Edad Axial y que tiene unas características distintas.

Durkheim sitúa a la práctica ritual como ese acontecimiento apropiador que produce un tipo de realidad diferente, la "efervescencia colectiva"7, el "éxtasis colectivo", la "energía emocional", es esa condición de posibilidad a través de la cual la gente experimenta una realidad diferente y más profunda. Así afirma que: "una vez alcanzado tal estado de exaltación, el hombre pierde la conciencia de sí mismo. Sintiéndose dominado, arrastrado, por una especie de fuerza exterior que le hace pensar y actuar de modo distinto a como lo hace normalmente, tiene naturalmente la impresión de haber dejado de ser él mismo. Le parece que se ha convertido en un nuevo ser: las galas con que viste, las especies de máscaras con las que se cubre la cara, son representaciones materiales de esta transformación,...Y como, al mismo tiempo, todos sus compañeros se sienten trasfigurados de la misma manera y exteriorizan su sentimiento en sus gritos, gestos y actitudes, todo se desarrolla como si realmente fuera transportado a un mundo especial, completamente diferente de aquél en que vive de ordinario, a un espacio poblado por completo de fuerzas excepcionalmente intensas, que le invaden y metamorfosean" 8 . La efervescencia colectiva que origina la trascendencia del mundo ordinario crea una plus extraordinario y el emblematisme subsecuente que él observa en las primeras sociedades humanas puede ser observado también en el simbolismo de las realidades nacionales en el siglo XIX, en medio de la intensificacion de la vida social creada por la Revolución Francesa, en el origen de la nación como la expresión protomoderna de la identidad colectiva. A juicio de Durkheim no habria una diferencia sustancial en cuento a la forma ritual entre la reunion de los cristianos que celebran los principales hitos de la vida de Cristo, los judios que recuerdan el Exodo de Egipto o una reunión de ciudadanos que conmemoran la promulgación de una nueva moral o un nuevo sistema legal o un acontecimiento significativo de la vida nacional. Tenemos que recordar que lo que hace reconocible al hecho religioso en cuanto tal no es su contenido sino su forma. Los contenidos de lo sagrado pueden cambiar a lo largo del tiempo, es decir, podrian ser establecidos y también podrian perder su aura de sacralidad. Cada sociedad crea sus propios contenidos sagrados. Lo que fue sagrado en el pasado podría ser menos sagrado hoy e incluso podría ser totalmente desacralizado en el futuro. Tenemos que recordar que el hecho religioso no es nada misterioso o sobrenatural, está presente en todas las civilizaciones y en todas las eras, pre-axial, axial y post-axial. Se manifiesta en sociedades que aparentemente son irreligiosas. No nace de sentimientos individuales, sino de estados propios del alma colectiva, pudiendo adquirir tantas formas como la colectividad que las engendra y solo puede determinarse su naturaleza a través de dos indicadores: las prácticas y las creencias. No debemos olvidar que lo sagrado en las sociedades modernas no es una constelación uniforme de símbolos y rituales que produce un consenso unánime entre todos los ciudadanos. Las sociedades modernas, en términos durkheimianos, tienen una conciencia colectiva plural con formas sagradas múltiples que algunas veces están en oposición entre ellas (G. Lynch, 2012, 135). Hablar de lo sagrado en las sociedades modernas significa mirar a las situaciones históricas contingentes (Th. A. Tweed, 2006, 54-79) que crean formas especificas de trascendencia -el elemento constitutivo de producción de sacralidad-, siendo algunas de estas todavia axiales y manifestándose en la mapificación de las religiones universales, pero surgiendo, y esto es lo que analizará el presente trabajo, otras formas con distintas características de tipo postaxial, tales como la sacralización de la nación y más recientemente la sacralización de la persona. No obstante, esta "realidad trascendental", y esto es lo relevante para Durkheim, tiene una génesis social, lleva el sello de la sociedad, es el producto de una trascendencia operada "desde dentro" de la sociedad, no tiene un origen supramundano, sino 
que es plenamente intramundana, es una trascendencia inmanente, nacida en el seno de las prácticas cultuales, tiene que encarnarse en una comunidad de culto antes que representarse en una comunidad de interpretación y de creencia, e incluso, nos atreveríamos a decir que, en el contexto de las sociedades modernas, es más relevante una solidaridad basada en prácticas compartidas que una solidaridad basada en creencias compartidas (Anne Warfield Rawls, 2004, 3)9.

II.

Comenzando con nuestra particular genealogía afirmativa de las expresiones de resacralizaciones modernas, fijémonos en el caso de la Revolución Francesa (Lynn Hunt, 1988, 25-44; Edward Tiryakian, 1988, 44-66). El abate Sieyés en su celebrado, Qu'es ce que le Tiers Etat, publicado en 1789, afirmó que la nación francesa era "un cuerpo de asociados que viven bajo leyes comunes y representados por la misma asamblea legislativa...Fue algo anterior, preexistente a todos los fenómenos e instituciones sociales... La imagen de la Patrie es la única a la que rendir culto" (E. Sieyés, 1970, 10-11). Según este fragmento podemos observar cómo la comunidad de salvación se transforma en una comunidad de culto, de prácticas, en una comunidad nacional imaginada, en los términos de Benedikt Anderson, en la que el nuevo objeto de culto es la nación, o mejor dicho, "el pueblo de la nación". El acontecimiento histórico no representa una transferencia de sacralidad, como apunta J. R. Llobera $(1994,187)$, que se mueve de lo sagrado a lo profano, como fue postulado habitualmente por la metanarrativa europea de la secularization, sino la sacralización de un dominio secular hecha posible por los actos revolucionarios performativos de 1789 y los años que siguieron a la revolución, creando de esta guisa una nueva constelación religiosa postaxial. De la Revolución Francesa emergió una voluntad constituyente representada en una nueva fe cuyos principios están contenidos en la Declaración de los Derechos del Hombre y del Ciudadano (A. Mathiez, (1904), 2012) 10. Lo real-regio se convierte en lo nacional. Esta sacralization transforma una realidad secular como la nación. Ya hemos visto como originariamente "lo secular" fue parte de un discurso teológico (saeculum), donde las formas seculares se independizan progresivamente de la tutela religiosa, pero, más tarde, como consecuencia del proceso de secularización, la categoría de "lo religioso" emergerá de los discursos político- seculares y de los discursos científico-seculares, algo que se pone de manifiesto en estas nuevas sacralizaciones postaxiales modernas (T. Asad, 2003, 192). Esta nueva metamorfosis de "lo religioso" sitúa a la religión como una categoría histórica y como un concepto universal globalizado dentro de los programas culturales y políticos de la modernidad secular occidental. La referencia durkheimiana es reveladora a este respecto: "Esta capacidad de la sociedad para erigirse en un dios o para crear dioses no fue en ningún momento más perceptible que durante los primeros años de la Revolución Francesa. En aquél momento, en efecto, bajo la influencia del entusiasmo general, cosas puramente laicas fueron transformadas por parte de la opinión pública en cosas sagradas, así la Patria, la Libertad, la Razón. Hubo la tendencia a que por sí misma se erigiera una religión con sus dogmas, sus símbolos, sus altares y sus festividades. ...Queda el hecho de que en un caso determinado, se ha visto que la sociedad y sus ideas se convertian directamente, y sin transfiguración de ningún tipo, en objeto de un verdadero culto" (E. Durkheim, 1982, 201).

Pero la efervescencia colectiva no es algo exclusivo de las convulsiones revolucionarias. Tomemos en consideración el ejemplo de la Europa de posguerra. Si algo es Europa, es un símbolo, un tótem, pero, para Durkheim, el tótem no es solo un símbolo de algo que es sagrado para el creyente sino que es una parte constituyente de lo sagrado en cuanto tal. Como ya hemos mencionado arriba, lo que es significante en el hecho religioso no es su contenido sino su forma, lo que es significante no es tanto la presencia o ausencia de seres sobrenaturales 
sino el potencial religador vinculante de determinados simbolos y prácticas sociales para los miembros del grupo. Las representaciones colectivas no son algo que existe per se, precisan de un vehículo capaz de actualizar sus potencialidades, precisan de eventos particularmente intensos en la historia que han sido realizados performativamente (J. C. Alexander, 2006a, 2991) a través de la efervescencia colectiva. Estos éxtasis colectivos capacitan al individuo para trascender su propia individualidad creando otro tipo de realidad, un nuevo ser, en términos durkheimianos. Esto ocurrió en el Europa en el espacio de tiempo inmediatamente posterior a la Segunda Guerra Mundial y la espantosa Shoah (R. Schwedberg, 1994, 378-387). Estos son eventos de shock colectivo, de crisis, de tragedia (recordemos, en este sentido, los enérgicos pronunciamientos, quizás olvidados hoy, de Winston Churchill en defensa de una Europa Unida en 1946, así como la fundación del Consejo de Europa en 1949, episodios que galvanizaron el movimiento proeuropeo) que elucidan una suerte de nuevo rito piacular postaxial y postnacional así como preludian un nuevo ideal político, el de una Europa Unida, nacida en oposición a la glorificación perversa nazi del estado nacional, aspectos estos que cristalizarán en el Congreso de la Haya en mayo de 1948. La nueva autorepresentación europea moderna sería, por tanto, el resultado de una identidad negativa, basada en hechos ocurridos en el pasado reciente. Jeffrey C. Alexander ha situado el Holocausto como el metaevento y la representación colectica dominante (2004, 196-264) que simboliza tal identidad colectiva negativa (mal) en la segunda mitad del siglo XX. Este meta-evento es comparable al meta-evento que representa el Sermón de la Montaña, si atendemos a sus implicaciones y repercusiones. Sin este conjunto de acontecimientos de reapropiación del pasado en el presente, Auschwitz no hubiese superado el estadio de crimen de guerra para convertirse en trauma cultural universal. Alexander da voz a la "experiencia de un trauma universal" (J. C. Alexander, 2013) que puede ser entendido como un proceso sociológico que define un daño doloroso inflingido a la colectividad, estableciendo las víctimas, asignando la responsabilidad y distribuyendo las consecuencias ideales y materiales como una forma de restablecer el bienestar de la comunidad.

Las ceremonias del Día de los Caídos en Guerra o Memorial Day así como los ritos subsidiarios del Armistice o el Veteran's Day en Estados Unidos, según Lloyd Warner (1959; 1962, 8), son rituales de un sistema simbólico sagrado que funciona periódicamente para unificar en una comunidad de culto (no de salvación) a toda la colectividad, con sus símbolos en conflicto y oposición, con sus iglesias y asociaciones autónomas. En este día, las angustias que el hombre padece, relacionadas con la muerte, son confrontadas con un sistema sagrado de creencias en torno a la muerte que proporciona tanto a los individuos como a la colectividad implicados en el ritual un sentimiento de bienestar11. El sentimiento de triunfo sobre la muerte que se consigue a través de la acción colectiva en el desfile del Memorial Day se hace posible al recrear el sentimiento de bienestar e incrementar la fuerza del grupo y del individuo en el poder del grupo, que tan intensamente se manifiesta durante los periodos de guerra o de crisis social, en los que surge esa efervescencia social creativa, esa "interacción intensificada, esa solidaridad social e intensidad de sentimiento" que "produce nuevas formas sagradas" (Warner, 1959, 273). Junto a las Navidades, el Día de Acción de Gracias y el 4 de Julio, el Memorial Day representa el calendario ceremonial de la sociedad americana. El Día de Acción de Gracias sirve para integrar a la familia dentro de la religión civil mientras el Memorial Day sirve para integrar a la comunidad local en el culto nacional. Este razonamiento no está lejos del que realiza el propio Durkheim: "Cuando la sociedad atraviesa circunstancias que la entristecen, angustian o irritan, desarrolla una presión sobre sus miembros para que testimonien por medio de actos significativos, su tristeza, su angustia, su cólera. Les impone como un deber que lloren, giman, se inflinjan heridas a sí mismos o a los demás; pues tales manifestaciones colectivas y la comunión moral que atestiguan y refuerzan, restablecen en el seno del grupo la energía que los acontecimientos amenazaban destruir y así le permiten reconstituirse" (FE, 584/380-381). Es esta la experiencia que el hombre interpreta cuando imagina la existencia de 
seres malévolos cuya hostilidad, solo puede aplacarse mediante sufrimientos humanos indirectos. Estos seres no son sino estados colectivos objetivados. Lo mismo ocurre con los poderes benévolos, que también son el resultado de la vida colectiva y su expresión, también representan a ésta, pero captada en una actitud muy diferente, a saber, en el momento en que se afirma con confianza y presiona con ardor para que las cosas concurran en la realización de los fines que ella persigue. Pero, "como ambos son con idéntico título estados colectivos, entre las construcciones mitológicas que los simbolizan se da un íntimo parentesco. Los sentimientos que se ponen en común oscilan del extremo abatimiento a la extrema alegría, de la dolorosa irritación al entusiasmo extático; pero, en todos los casos hay comunión de conciencias y mutuo consuelo como consecuencia de tal comunión....En definitiva, es la unidad y diversidad de la vida social la que determina, a la vez, la unidad y diversidad de los seres y cosas sagradas" (E. Durkheim, FE, 591/385, Énfasis mío; W. S. F. Pickering, 1984, 129). Cuando nos referimos a la religión, no debemos olvidar que "no existe una regla global" (J. Casanova, 2006b, Vol. 8, Nos 1 y 2, 17).

La ceremonia de coronación de la reina Isabel II en la monarquía británica en 1953, nos ofrece a juicio de Edward Shils y Michael Young (1953, 63-82) una excelente oportunidad para constatar cómo en contextos sociales particulares y en momentos históricos específicos, una figura específica o una institución pueden llegar a representar el "centro sagrado" 12 de la sociedad. La participación popular a lo largo del país fue un acto de "comunión nacional" (Shils y Young, 1953, 67, 70-71, 80) ya que suministró a través de un acontecimiento apropiador excepcional y para prácticamente toda la sociedad británica un contacto intensivo con lo sagrado (Shils y Young, Ibidem, 80) encarnando "muchas de las propiedades de una realización ritual religiosa" (Shils y Young, Ibidem, 72), en la que la mayor parte de los ingleses de a pie quedaron prendidos del espíritu del acontecimiento de forma extraordinaria y se comunicaron el entusiasmo entre sí. No obstante, sin dejar de reconocer las indudables muestras de adhesión ritual que concitó la ceremonia de Coronación, es decir, del éxito performativo de recrear una comunidad moral de culto, después de dos guerras mundiales (en un contexto social de crisis en el que la Familia Real durante la Guerra Relámpago permaneció en Londres) y la Gran Depresión (Shils y Young, Ibidem, 76), no es menos real la crítica de Norman Birnbaum $(1955,5-23)$ y de Steven Lukes $(1975,289-308)$ a Shils y a su defensa de un "núcleo central sagrado de valores", de un "consenso de valores" a la Parsons en medio de una sociedad avanzada con una profunda indeterminación de la conciencia colectiva, con una división de clases, de estilos de vida e ideologías contrapuestas que cohabitarán el incipiente Estado de Bienestar que entonces comienza su andadura.

El concepto de "religión civil americana" acuñado por Robert N. Bellah (2006, 225-245) ofrece un ejemplo genuinamente moderno de resacralización de la realidad secular de la nación. Si Durkheim nos ha ofrecido el jugoso ejemplo de la Revolución francesa, Bellah extraerá una serie de importantes conclusiones a partir de "una colección de creencias, símbolos y rituales en relación a las cosas sagradas e institucionalizada en una colectividad (la república americana)" (R. N. Bellah, 2006, 233). Los hitos de emergencia de la "religión civil" se producen en medio de periodos de explosión sociopolítica, de crisis que ponen a prueba la creatividad social de un colectivo. El primero de estos períodos está representado por la guerra revolucionaria de independencia contra Inglaterra, donde George Washington emerge como el Moisés que conduce a su pueblo rompiendo las cadenas de la tiranía. El segundo período se forja en torno a la Guerra Civil, el "centro de la historia americana", momento que recoge la intensidad trágica de una lucha fratricida en una de las guerras más sangrientas del XIX. Mientras el primer período se centró en la cuestión de la Independencia, en si el país emergente debiera o pudiera autogobernarse, el segundo se concentró en la idea de esclavitud que a la postre representaría el problema de mayor alcance para la completa institucionalización de la democracia dentro del país. La Guerra Civil trajo consigo las cuestiones más profundas de significado nacional y Abraham Lincoln, "nuestro presidente 
mártir" (Bellah, 2006, 236), aparecerá como el nuevo Jesús que recoge el testigo de Washington con nuevos desafios a los que responder. El tercer periodo de desafio, Bellah lo sitúa en medio de la crisis por las consecuencias en la esfera pública de la Guerra de Vietnam y la efervescencia colectiva que genera el movimiento de los derechos civiles.

Aunque tras el primer periodo de la "religión civil" destacan arquetipos bíblicos como el "Israel americano", "Exodo", "Pueblo Elegido", "Tierra Prometida", "Nueva Jerusalém" y tras el segundo periodo destacan arquetipos cristianos como el de "Muerte Sacrificial y Renacimiento" (Bellah, 2006, 245), "el Dios de la religión civil no es un Dios "unitarista", ...(sino que) está más relacionado con el orden, la ley, la libertad y la justicia que con la salvación y el amor" (Bellah, 2006, 232) -de hecho J. F. Kennedy en su discurso inaugural sitúa como enemigos no a otros hombres sino a la tiranía, la pobreza, la enfermedad y la guerra-, es decir, la religión civil es una comunidad nacional de culto pero no una comunidad de salvación, "es algo genuinamente americano y nuevo. Tiene sus propios profetas y sus propios mártires, sus propios acontecimientos sagrados y sus propios lugares sagrados, sus propios rituales solemnes y sus símbolos" (Bellah, 2006, 245). En este sentido, la religión civil es una religión postaxial, reordena la presencia de rasgos hebraicos y otros cristianos en un contexto nuevo. Bellah retoma el ejemplo de Tocqueville a quien cita: "La parte más grande de la América británica estaba poblada por hombres que, después de haber desafiado la autoridad del Papa, no reconocieron ningún otro tipo de supremacía religiosa: se llevaron consigo al nuevo mundo una nueva forma de cristianismo que no puedo describir mejor que llamándolo religión democrática y republicana" (R. N. Bellah, 2006, 239) 13. Esta no fue nunca algo anticlerical ni militantemente secular, por el contrario, se nutrió selectivamente de la tradición religiosa de tal manera que el americano medio no vio ningún conflicto entre ambas. Los recién llegados, cada uno con su credo religioso, fundaron un metacredo civil en el cual encontraron acomodo todos, una especie de "igualdad metafisica u ontológica de creyentes". Precisamente, como estrategia de evitación y superación de las guerras de religión en Europa, en América se procede a una separación entre la iglesia y el Estado (algo que garantiza la Primera Enmienda cuya orientación es prorreligiosa, es decir, a ningún creyente se le podrá impedir el ejercicio de su fe), en la convicción de que ninguna iglesia-estado representa el elenco de denominaciones religiosas que confluyen en el espacio de la sociedad civil americana. Digo, separación entre iglesia y estado que no entre religión y política. La religión va a ser una parte importante, no sólo de la "cultura" sino de la política de los Estados Unidos y prueba de esto son los continuos y recursivos revivals religiosos.

El proto-evento del 11 de septiembre de 2001, en Nueva York, la destrucción del WTC que originó la muerte de 2998 personas y 6291 heridos, tiene también importantes repercusiones en los rituales que crean y recrean la nación. Aunque inicialmente el acto terrorista, ritualmente, significó un atroz derramamiento de sangre -tanto literal como metafóricamentehaciendo uso de los fluidos vitales de las víctimas para arrojar una pintura beligerante y horrenda sobre el lienzo de la vida social (J. C. Alexander, 2006b, 91-115), sin embargo, en una segunda fase, la destrucción del WTC, contra-performativamente, congregó a la gente en un acto ritual transcultural, interracial e interclasista en el que todo el mundo gritó, en medio de un gran rito piacular como signo de duelo: "We all are americans". El nuevo espacio social (Ground Zero) y el nuevo tiempo (911) crean las condiciones de posibilidad para la comunión de conciencias en un acto de fusión social exitosamente realizado para constituirse en el centro de lo social, a la manera de un "hecho social total", en los términos de Marcel Mauss. La reacción social al ataque representa un acontecimiento apropiador inmune a la diferenciación social en el que un trauma cultural ha resacralizado ciertos discursos en la esfera pública. La aflicción pública y la rememoración de los eventos del 9/11 se convierten en el contra-modelo ritual de un drama sagrado que evoca adhesiones nacionales e internacionales con las víctimas del asalto como simbolos sagrados de libertad y democracia. Lo que es interesante subrayar es que aquello que ha creado un tipo de comunión moral, incluso en una sociedad 
funcionalmente diferenciada, no es el hecho de compartir todos las mismas creencias, puesto que Estados Unidos es una sociedad pluralista y diferenciada en lo cultural, sino el hecho de compartir las mismas prácticas en el seno de la esfera pública en la que una creatividad social emergente re-encantó y re-armó moralmente a la sociedad. No obstante, como muy acertadamente apunta Gordon Lynch: "Los eventos del 9/11, no solo demuestran cómo, en las sociedades pluralistas, los rituales sagrados no solo obtienen la respuesta pretendida de sus respectivas audiencias sino que muestran cómo las actividades rituales y las contraactividades rituales relacionadas con lo sagrado pueden estar implicadas en modelos arraigados de conflicto violento" $(2012,45)$.

Continuando con los fenómenos de resacralización moderna de ciertos ámbitos seculares, Alexander ha explorado hasta qué punto en las elecciones presidenciales americanas, el político debe aparecer como un "nuevo profeta" (J. Alexander, 2010a, 2014) en un tiempo secular resacralizado, cuya principal tarea es construir un mito, una nueva constelación de significado, que a través de la efervescencia colectiva que emerge en los rituales colectivos es entronizado en el panteón de los héroes de la nación. Para forjar esta narrativa cuasiescatológica, el "nuevo profeta" debe luchar democráticamente con los otros adversarios políticos en los diferentes escenarios de la esfera pública. Alexander analiza la lucha politica en las elecciones presidenciales de 2008 (y también de 2012), en las que Hillary Clinton simbolizó las ideas-fuerza de igualdad y movilidad social, una heroina de la clase obrera, una supermujer rompiendo el techo acristalado. John McCain simbolizó al prisionero de guerra herido que rompe los límites de la esclavitud, enfrentando la corrupción, siendo inconformista y poniendo de manifiesto una vida nuevamente altruista. Barack Obama se convirtió en el gran emancipador, calmado y razonable, representando al Abraham Lincoln negro que prometió una solidaridad más profunda y extendida. El restauraría el pluralismo democrático americano reflejado en el motto "e pluribus unum" de la Constitución y permitiría a los americanos hablar con autoridad moral y respeto al resto de las naciones. En su discurso de nominación, por el Partido Demócrata, él no presenta nuevos hechos, sino una nueva narrativa temporal, se apropia el tiempo, prometiendo un nuevo estadio que va del espacio de experiencia de los males del pasado y el presente que ha heredado a un horizonte de expectativas sagrado y renovado, haciendo del sueño una realidad. La fuerza para él no está en el dinero ni en el poder político o militar sino en la promesa americana. Actuó como el sujeto en el que se reflejó América. Se presentó como el portador del regalo que ha alcanzado la gente que se refleja en él, no como lo que uno es, no como el político separado del pueblo que habita la Casa Blanca sino como aquél que le gustaría ser, como aquél profeta que realiza el sueño americano. Pero, la pregunta que surge más tarde o más temprano es la siguiente: ¿Por qué emergen estos perfiles proféticos en un mundo predominantemente secular?. Siguiendo la interpretación durkheimiana (y también weberiana, porque no decirlo) podemos afirmar que el héroe se forja a sí mismo en tiempos de crisis, trascendiendo la experiencia inmanente intramundana, la vida ordinaria, proyectándose como portador de una promesa sagrada de reparación civil. Esto no es nuevo, los nacionalismos a lo largo del siglo XIX en Europa ya construyeron mitomotores religiosos dentro de sus formatos seculares, como hemos visto previamente en los trabajos de Peter van der Veer y de Talal Asad. El politico proyecta una imagen que solo alcanzará eficacia simbólica si en la lucha democrática performativa contra sus adversarios alcanza la "posición del rey cargado de aura sagrada", en un "proceso mágico" en el que los votos secretos de los ciudadanos son transformados en una voluntad general públicamente proclamada.

Llegados a este momento convendría resumir brevemente el conjunto de características que jalonan los procesos de resacralización de esa instancia ubicada en el ámbito secular, la nación, que hemos analizado.

En primer lugar, lo que caracteriza a la emergencia de toda forma religiosa (con sus respectivos contenidos) es la trascendencia del ámbito del mundo de la vida14 y la forma en que esto 
ocurre, el mundo de lo sagrado tiene una génesis social a partir del ritual, de la intensificación de la vida social por medio de la efervescencia colectiva, con el objetivo de crear una realidad distinta, interdicta y separada de la anterior. Esta es una "trascendencia inmanente", una "trascendencia desde dentro". Esto es algo muy distinto del paradigma ontológico (R. Otto, 1985) según el cual el mundo trascendente funge de realidad ontológicamente suprema, el Misterio, lo "totaliter aliter", lo "absolutamente otro", inmutable, dado, no creado a partir de la interacción social intensificada. Lo sagrado solo puede surgir a partir de la existencia intensificada de los seres humanos que interactúan y transforman el mundo ordinario, creando un mundo extra-ordinario. Pensamos, de forma equivocada, en lo sagrado como en el ser puro auto-subsistente, como la santidad augusta, pero en realidad lo sagrado es algo ambivalente que está diferenciado internamente entre las fuerzas puras e impuras (E. Durkheim, 584, 380381), de hecho, para Thomas Mann, "la cultura no es otra cosa que la devota y ordenadora, por no decir benéfica, incorporación de lo monstruoso y de lo sombrío en el culto de lo divino" $(1992,15)$. El mal no es una aberración -un fracaso- en un mundo por otra parte ordenado por la razón. Más bien representaría el esfuerzo de hacer el mundo de otra forma, de crear sentido de otra manera. En ese nuevo mundo -el mundo del mal-, la muerte se proyecta en el otro. Aristóteles apuntó que toda acción humana es motivada por una percepción del bien, quizás, nosotros podíamos decir que toda acción humanan contiene el germen del mal. Una de las lecciones del Génesis es que podemos hablar coherentemente del mal solo allá donde podemos hablar de sujetos libres. Solo el actor libre trae consigo el mal al mundo. Solo en la medida en que el mal está relacionado con la libertad, está asimismo relacionado con la muerte. En el Génesis, "la muerte es consecuencia de un acto libre. Tendremos razón al cuestionar el orden: el acto libre a partir del cual emerge el mal pudiera ser una consecuencia de nuestra conciencia de la muerte. Si fuéramos inmortales, no existiría nada a lo cual etiquetar como mal. La mortalidad es el elemento clave" (Paul W. Kahn, 200713). Pensamos lo sagrado como lo divino, pero, en realidad lo divino es solo una parte de lo sagrado. Jane Ellen Harrison, filóloga y mitóloga británica contemporánea del propio Durkheim, afirma que "le sacré, c'est le père du Dieu", en un magnífico trabajo publicado el mismo año que Las formas elementales..., (Themis. A Study of the Social Origins of Greek Religion, 1912, 63), donde analiza siguiendo el enfoque de Durkheim, la génesis social de las representaciones colectivas sagradas presocráticas basadas en el culto al daimon y la transición a la religión olímpica y al Logos socrático posterior. Moira sencillamente significa "parte" o "lote asignado" y de aquí se deriva el significado de "destino". Tanto los dioses como los hombres tienen moirai. Cada Dios posee su parte o dominio asignado, esto es, cierto espacio de la naturaleza o campo de actividad. La Moira preaxial está por encima de todos y cada uno de los dioses axiales y los límites que impone a sus poderes son de naturaleza social y moral. Hesíodo, destaca mediante la secuencia temporal, la preponderancia de la Moira sobre las divinidades que nacerian después. El orden de la cosmogonía de Hesiodo implica que la división del mundo en dominios era más antigua que los dioses y, a la vez, afirma, que estos tomaron forma en sus respectivos dominios y surgieron de esos mismos elementos. Así la voluntad de los dioses comienza a hacer valer sus pretensiones frente a la inevitable asignación del destino. El poder impersonal de la Moira se personaliza en los diferentes dioses, así se comienza a hablar del "hado de Zeus" o del "destino de Dios".

Esta mutación cultural es corroborada en el análisis sobre la génesis social de los estadios de evolución de la cultura y de la cognición desarrollados por Merlin Donald (1990) que distingue un primer estadio en la cultura mimética desarrollada por el Homo Erectus, es decir, los primates y los australopitecos, hace 2.000 .000 de años, donde se pone de manifiesto un aumento del tamaño del cerebro y la emergencia del más básico de los niveles de representación, la habilidad imitativa para reeditar eventos. La mímesis es un modo gestual de expresión que es inherentemente reduplicativo y colectivo en su naturaleza, convierte la arena pública de la acción en teatro. La forma primordial distintivamente humana de cultura está 
orientada performativamente. Los humanos son actores y, inicialmente, en su forma arcaica, el rostro público de esa cultura mimética ha sido un teatro de acción personificada, manifiesta en la emergencia de patrones ritualizados de cultura práctica, como las migraciones estacionales coordinadas, los campamentos compartidos y alguna división rudimentaria del trabajo. E1 Homo Erectus tuvo la habilidad de ensayar y evaluar y así afinar sus propias acciones. El entrenamiento es esencialmente una acción mimética donde el individuo debe repetir una actividad performativa previa con la finalidad de practicarla y mejorarla. Este tipo de imaginación mimética sobrevivirá en la naturaleza esencialmente teatral de las relaciones humanas (E. Goffman, 1981; R. Collins, 2009), así como en la música y en las artes visuales. La transición del Homo Erectus al Homos Sapiens (250.000-100.000 años) marca un nuevo estadio evolutivo, el representado por la cultura mítica, caracterizada por el surgimiento del sistema del habla, como nueva modelización del universo de la existencia humana, así como por el surgimiento de la la metáfora y la narrativa. Este tránsito de una forma puramente mimética de cultura al lenguaje hablado, a la narrativa, y a una cultura oral-mítica completamente desarrollada supone un desarrollo revolucionario que precipita un tránsito en la representación propia de las costumbres miméticas de movimientos lentos hacia la capacidad narrativa grupal. Esta adaptación introduce un nuevo estrato de cultura con la consecuencia de que tanto la cognición humana como las formas culturales asociadas se hacen más complejas y diversificadas. La expresión pública de esta nueva habilidad narrativa se manifiesta en una imaginación liberada que faculta a los seres humanos a reorganizar eventos más complejos en la imaginación o incluso a inventar eventos ficticios, como ocurre en la narrativa y en la fantasía, permitiendo de esta guisa la emergencia de variaciones sin limite en cuanto a cómo la realidad del grupo pudiera ser construida. Hace aproximadamente 40.000 años, surge un tercer estadio, la cultura teórica, y el "hardware" que contribuye al despliegue de esta nueva adaptación no es ya biológico sino tecnológico y esta apoyado en la invención gráfica, en la construcción teórica y en el despliegue de una memoria externa. El cerebro humano ha co-evolucionado junto a sus culturas cognitivas a lo largo de más de dos millones de años y ha alcanzado un punto donde no puede realizar su diseño potencial fuera de la cultura. La estructura de la mente se ha fijado cada vez menos en el neocortex. A medida que progresa la evolución, actuamos dentro de "colectividades cognitivas" en simbiosis con sistemas externos de memoria como las religiones del Libro, los museos, las bibliotecas, templos, monumentos, etc. Esta tercera transformación ha conducido a una de las más grandes reconfiguraciones de la estructura cognitiva, sin grandes cambios genéticos en la historia de los mamíferos -de hecho, nuestros genes son prácticamente idénticos a los de un chimpancé o un gorila, pero nuestra arquitectura cognitiva no lo es. Está indisociablemente unida a esas "colectividades cognitivas". Nos hemos hecho más complejos, multidependientes, mentes híbridas, portando dentro de nosotros, tanto como individuos como sociedades, toda la herencia evolutiva de los dos pasados millones de años. Habitualmente pensamos que la fase mimética de nuestro desarrollo como seres humanos es superada por la fase simbólica, donde construimos imágenes y representaciones simbólicas de la realidad, y que ésta fase es superada en la fase conceptual-teórica donde el pensamiento abstracto hace tabula rasa de todo lo anterior, pero, no sucede esto, un nuevo estadio supone más bien una reconfiguración de viejas y nuevas posibilidades, en lugar de una superación y desaparición de los estadios anteriores. Lo interesante del modelo de Donald frente a todo historicismo o teleologismo ilustrado, es que nos permite entender las fases evolutivas sin un sesgo finalista en donde la cultura teórica habría erradicado los desarrollos mimético y mítico.

En segundo lugar, como hemos tenido oportunidad de ver en las diferentes descripciones de resacralizaciones modernas que afectan a la nación, lo sagrado en las sociedades modernas se caracteriza por la emergencia conflictiva de múltiples formas sagradas (G. Lynch, , 2012, 49), algunas de ellas en abierta pugna simbólica. En el análisis que hemos realizado hemos observado que los rituales religiosos juegan, sin duda alguna, un rol crucial en la integración 
de las sociedades industriales modernas, pero Steven Lukes (1975, 297 y ss) critica acertadamente a los neodurkheimianos -Shils $(1953,65)$, Verba, Warner y en menor medida Bellah- el hecho de sobrevalorar el consenso de valores - lo que Shils llama el "sistema central de valores"- al objeto de mantener el equilibrio del sistema social -"el problema del orden"- en las democracias liberales. Lukes afirma que hay que demostrar primero si la sociedad realmente se mantiene unida, en qué medida lo está y en qué forma lo consigue. Algunos de los rituales que hemos analizado expresan un simbolismo hegemónico dominante, pero existen otros rituales contemporáneos que expresan actitudes y valores alternativos y no oficiales, por ejemplo, las marchas alternativas al Memorial Day organizadas como protesta contra la Guerra de Vietnam o las marchas del Primero de Mayo en los países capitalistas (como opuestas a las de los países comunistas), o las marchas del Día de San Patricio en Nueva York, o las marchas de grupos alternativos en los momentos álgidos del Mayo francés en 1968 (J. Berger, 1968), o las marchas rituales de la Orden de Orange en Irlanda del Norte (R. Rose, 1971, 258), caso este último en donde las efervescencias colectivas sirven no tanto para unir a la comunidad como para fortalecer a los grupos dominantes dentro de ella. En todos estos casos, aplicando las interpretaciones neodurkheimianas, se puede mostrar, al contrario que en el caso anterior, cómo las efervescencias colectivas pueden servir para integrar y fortalecer a grupos sociales subordinados, bien estén estos implicados de alguna manera en la lucha dentro del orden social existente, o bien intenten desafiarlo o en el caso extremo derribarlo. Estos rituales, de alguna manera, contribuyen a la integración social pero no al consenso de valores, de ahí que consideremos empíricamente más viable alcanzar la solidaridad social por medio de prácticas rituales comunes que por medio de creencias y valores comunes. Según la propuesta de Lukes $(1975,302)$ deberiamos preguntarnos por algunas cuestiones que los neodurkheimianos olvidan, puesto que la ritualización tiene lugar en el seno de un modelo de sociedad pluralista, estructurada en clases y conflictiva, deberiamos preguntarnos por las estrategias simbólicas usadas por diferentes grupos, bajo específicas condiciones estructurales, para defender o para obtener el poder vis-a-vis otros grupos, así como por las maneras en que el simbolismo ritual puede proporcionar una fuente de creatividad e improvisación, un contramodelo ritual y una fuerza antiestructural, que engendre nuevas formas sociales, culturales y políticas, que comportan lo que Víctor Turner ha llamado "liminaridad". Muchos de los rituales analizados pueden servir, sin duda, para reforzar y perpetuar los modelos dominantes y oficiales de estructura social, como por ejemplo, el "reino", el "imperio", la constitución, la república, la nación, el Estado socialista, la "democracia", una "sociedad libre", el "imperio de la ley", el "interés público", el "socialismo", la "legalidad socialista", el "camino al comunismo". Las ceremonias oficiales como la Coronación de la reina Isabel II, los Días de la Independencia, de Los Caidos en la Guerra, de la Bastilla, los Discursos Inaugurales de los presidentes de Estados Unidos, las movilizaciones de masas en los casos de magnicidios políticos como el de Martin Luther King, J. F. K., Isaac Rabin, o el centenario de Lenin y las visitas multitudinarias a su mausoleo, o las marchas de la Revolución de Octubre, todos estos actos rituales, que lo son, invocan lealtades hacia una cierta representación poderosamente evocada del orden político y social, pero, muchas otras actividades institucionalizadas o no, que no están primariamente identificadas por sus participantes como rituales, sin embargo, juegan exactamente el mismo papel.

En tercer lugar, los rituales y las formas sagradas analizadas son contexto-dependientes. A partir del hecho sociológico procedente de un contexto histórico concreto, el de las dinámicas de transformación del cristianismo europeo-occidental desde la Edad Media hasta nuestros días, según el cual una Era secular solo puede emerger a partir de la evidencia empírica de que "la creencia en Dios ya no es algo axiomático, (de que) hay alternativas" (Ch. Taylor, 2007, 3), se ha construido una teoría general de la secularización apoyada en una "conjetura sociológica" que funge de "régimen de conocimiento" con connotaciones no solo descriptivas sino prescriptivas y que podiamos formular, en los términos de José Casanova, de la siguiente 
forma: "cuanto más moderna, más secular es una sociedad, y cuanto más secular, menos religiosa" (J. Casanova, 2006a, 17), conjetura que a la postre ha resultado falsada en términos empíricos. Esta teoría general de la secularización en Europa ha funcionado como una profecia que se autocumple (J. Casanova, 2002, 24) en la medida en que una mayoría de la población en Europa ha venido a aceptar las premisas de esta teoria como un hecho normal (cuando, en realidad, Europa es un islote de excepcionalidad secularista frente al océano habitual de persistencia del hecho religioso en el resto del mundo) y las ha proyectado como un original del que realizar copias world wide, poniéndose de manifiesto que modernización y secularización, empíricamente hablando, no son dos términos sinónimos. Cuando nos referimos a la religión, no debemos olvidar que "no existe una regla global" (J. Casanova, 2006b, Vol. 8, Nos 1 y 2, 17). $\mathrm{El}$ excepcionalismo americano (y el europeo coextensivamente), tienen su origen en condiciones históricas contingentes.

En cuarto lugar, es importante notar que los episodios de resacralización descritos que afectan a la nación tienen un carácter postaxial, es decir, no suponen una versión actualizada de las religiones monoteístas sino que representan nuevas y originales formas sagradas que emergen en competencia con otras formas sagradas y a su vez con las instancias seculares, lo cual confirma el supuesto durkheimiano con el que comenzábamos este trabajo al sostener que el hecho religioso tiene que ver más con la acción que con la fe y el dogma, con la capacidad para trascender la pura facticidad de la vida ordinaria sacralizando ámbitos de la existencia que no son necesariamente seres sobrenaturales o misteriosos.

III.

Otro ámbito en el que se produce un proceso de resacralización moderna postaxial es el de la persona humana. En este sentido, la autoridad principal del renacimiento de lo sagrado (y también de las religiones) no habría que buscarla fuera del sujeto, sino dentro del sí mismo soberano (U. Beck, 2008, 46 y ss).

En la determinación de la génesis de la individualidad moderna, Hans Joas ha acuñado el concepto de "sacralización de la persona" (H. Joas, 2011, 81-100) 15 a partir de la obra de Emile Durkheim. El indicador social que utiliza como núcleo de su propuesta es la génesis de las formas de castigo en el derecho, haciendo una importante crítica del concepto de disciplina que procede tanto de la tradición de la ilustración (representado en la obra de Cesare Beccaria) como de la genealogía postilustrada (representada por Michel Foucault). Supongamos, plantea Joas, que es la inclusión social, más que la disciplina, lo que proporciona la clave de comprensión de los importantes cambios sociales que suceden a lo largo del siglo XVIII y que tantas repercusiones van a tener. La inclusión hace referencia a la integración en la categoría de ser humano, es decir, alude a la integración de aquellos -como los criminales y los esclavosque no habian sido incluidos previamente dentro de los límites de este concepto. Más bien, "lo que fue considerado como el peor crimen posible en la historia del sistema penal ha sido siempre un acto dirigido contra lo que constituye el núcleo sagrado de una comunidad" $(\mathrm{H}$. Joas, 2008b ,169-170). Si presuponemos esto, entonces, parece razonable entender los cambios en el sistema penal a partir de cambios en la comprensión de lo sagrado. Por esta razón hablamos de "sacralización de la persona". Desde esta perspectiva, las reformas del derecho penal y la práctica penal, así como la creación de los derechos humanos a finales del siglo XVIII, son una expresión de un profundo cambio cultural, a través del que la persona humana se convierte en un objeto sagrado. Ha sido Emile Durkheim, a juicio de Joas, el primero en captar esta importante idea. Durante la agitación producida por el escándalo del 
caso Dreyfus, escribió: "Esta persona humana (personne humaine), cuya definición es como la piedra de toque que distingue el bien del mal, es considerada sagrada en el sentido ritual del mundo. Participa de la majestuosidad trascendente que las iglesias de todos los tiempos han atribuido a sus dioses; es concebida como un ser investido con tal propiedad misteriosa que crea un vacío en torno a las cosas sagradas, sacándolas del contacto vulgar y retirándolas de la circulación habitual. El respeto que se le da procede precisamente de esta fuente. Cualquiera que atenta contra la vida humana, contra la libertad humana, contra el honor humano, inspira en nosotros un sentimiento de horror análogo al que experimenta el creyente cuando observa que su idolo ha sido profanado. Tal moral no es simplemente una disciplina higiénica o una buena economía de la existencia, es una religión donde el hombre es, a la vez, fiel y Dios" (E. Durkheim, 1973, 264-265. Enfasis mío). Durkheim no proporciona propiamente una teoria del proceso de sacralización. Él vincula las particularidades de la sociedad moderna a una energia creciente que procede de que "los sentimientos que tienen por objeto al hombre, se han vuelto muy fuertes...El grupo... es solo el medio para realizar y desarrollar la naturaleza humana... La calidad del hombre,..., se ha convertido naturalmente en objeto por excelencia de la sensibilidad colectiva" (E. Durkheim, 2006, 133). La creación de los derechos humanos no es sino parte de este proceso de inclusión y de sacralización de la persona humana y de la coextensiva sacralización de la humanidad. Este concepto de sacralización de la persona no tiene nada que ver con la glorificación egocéntrica del propio yo sino con la personalidad humana (E. Durkheim, 1973, 268; H. Joas, 2007, 151-168). El resorte de esta fe en la persona no es el egoísmo sino la simpatía por todo lo que el hombre representa, un gran sufrimiento por todos los dolores que aquejan al hombre, por las tragedias humanas, un compromiso para luchar contra ellas. Para Durkheim la "sacralidad de la persona" no es un sistema posible de creencia con efectos de integración social sino el único sistema de creencias que puede asegurar la unidad moral de un país. Enfatizando la relevancia de los procesos modernos de interacción ritual, Erwing Goffman también muestra la presencia del muy moderno proceso de sacralización del hombre: “...En un sentido, este mundo secular no es irreligioso como podriamos pensar. Muchos dioses han desaparecido, pero el individuo tozudamente permanece como una deidad de considerable importancia. Camina con alguna dignidad y es el objeto de muchos ofrecimientos vitales. Esta celoso de la adoración que se le tributa y esta preparado para perdonar a aquellos que lo han ofendido. Debido al estatus de ciertas personas relacionadas con él, en algunos casos se le considerará como algo contaminante, mientras en otros casos esas mismas personas serán quienes le contaminan a él, siendo conscientes de que en cualquier caso deben tratarlo con cuidado ritual. Quizás, el individuo es tan viable como Dios porque puede actualmente comprender el significado del ceremonial de la forma en que es tratado y a partir de sí mismo puede responder a lo que se le propone. En contacto con tales deidades no hay necesidad de intermediarios, cada uno de estos dioses es capaz de servir a su propio sacerdote" (E. Goffman, 1967, 95).

La "sacralización de la persona" puede ser verificada también a través de otro indicador. De hecho podemos asumir la significancia del cristianismo como un prerequisito cultural para la emergencia del individualismo moderno. Durkheim ya era consciente de esta influencia cristiana cuando afirma: "El cristianismo expresa en una fe interior, en la convicción personal del individuo, la condición esencial de la divinidad...El centro de la vida moral ha sido así transferido de afuera hacia dentro y el individuo se ha situado como el juez soberano de su propia conducta no precisando recurrir a otros criterios que no sean él mismo y su Dios" (E. Durkheim, 1973, 68). En este sentido, podemos confirmar con José Casanova (J. Casanova, 2011, Vol. 59, 2, 265) la visión de Durkheim, ya mencionada por Hans Joas, según la cual el culto al individuo se convierte en religión de la modernidad, solo que en este caso, la transformación se produce en el seno de la propia religión católica. Durkheim seguía, con matices, una línea de argumentación que ya habian iniciado profetas de la ilustración como Saint Simon y Comte cuando postularon que más tarde o más temprano una nueva religión de 
la humanidad (E. Durkheim, 1973, 48) 16 reemplazaria a las religiones teocéntricas. El proceso de transformación del catolicismo a lo largo de la segunda mitad del siglo XX, el proceso de su democratización interna, que se ha venido en llamar aggiornamento, confirma la visión de Durkheim sobre la sacralización de la persona operada en la modernidad avanzada, pero lo que ninguno de estos profetas y padres fundadores de la sociología positivista pudo haber anticipado es que, paradójicamente, los viejos dioses y las viejas religiones, cuya muerte Durkheim anunció 17, han ganado nueva vida convirtiéndose en portadores del proceso de sacralización de la humanidad, como ocurre en el caso de la iglesia católica. La sacralización de la persona y coextensivamente de la humanidad quedan plasmados en la globalización de los derechos humanos. Casanova ha demostrado de forma consistente que la aceptación por parte de la iglesia, durante el Papado de Juan XXIII, de la doctrina moderna de los derechos humanos universales ha alterado radicalmente las dinámica tradicional de las relaciones iglesia-Estado así como el rol de la iglesia tanto nacional como transnacionalmente. Desde un punto de vista teológico, "esto conlleva la transferencia del principio de la libertas ecclesiae, que la iglesia ha guardado tan escrupulosamente a través del tiempo, a la persona humana individual -a la libertas personae (J. Casanova, 1997, 212 y ss). En este proceso, el Papa podría experimentar una curiosa transformación de ser el santo Padre de todos los católicos para convertirse en el padre común de todos los hijos de Dios y en el portavoz autoproclamado de la humanidad, en defensor hominis. Quizás, la diferencia fundamental radica en que la espada del poder espiritual no puede ya buscar la protección de la espada del poder temporal con el objeto de ejercer su autoridad contra los regímenes religiosos en competencia en orden a obtener el monopolio de los medios de salvación, lo cual dejaría sin valor el dogma católico del extra ecclesia nulla salus.

IV.

En este apartado final, y una vez analizados los procesos de resacralización de dos ámbitos seculares como son la nación y la persona, voy a analizar, tomando como referencia la propuesta del politeísmo de valores de Max Weber, la estructura de la lucha simbólica existente entre ambas formas sagradas, fijándome en dos estudios de caso que proceden de historias recientes de Irlanda del Norte y del País Vasco.

Hay una serie de fragmentos de Weber que concentran la visión de Weber sobre la estructura politeísta de valores de las sociedades modernas. En el Excurso dedicado a las Teorias de los estadios y direcciones del rechazo religioso del mundo, cuya primera versión data de 1915, "la racionalización y consciente sublimación de las relaciones del hombre con las esferas de posesión, interna y externa, religiosa o mundana, de bienes culturales, condujo a que se hicieran conscientes en sus consecuencias las específicas legalidades (lógicas) internas (innere Eigengesetzlichkeiten) de cada esfera en particular y a que entraran por ello en aquellas tensiones mutuas que estaban veladas a la ingenua relación originaria con el mundo exterior. Esta es una consecuencia muy común de la evolución de la posesión (intra y extramundana) de valores hacia lo racional, hacia la búsqueda consciente y hacia la sublimación por el conocimiento"18. En otro fragmento Weber apostilla inequivocamente: "El destino de una época que ha comido del árbol del conocimiento es que debe(....) reconocer que las nociones generales sobre la vida y el universo nunca pueden ser producto de un creciente conocimiento empírico, y que los más altos ideales que nos mueven con la mayor fuerza siempre se forman sólo en la lucha con otros ideales que son tan sagrados para otros como lo son los nuestros para nosotros" (M. Weber, 1982, 46). Para Weber, "los numerosos dioses antiguos, desmitificados y convertidos en poderes impersonales, salen de sus tumbas, quieren dominar 
nuestras vidas y recomienzan entre ellos la eterna lucha....Toda ésta búsqueda de vivencia procede de una debilidad, pues debilidad es la incapacidad para mirar de frente el rostro severo del destino de nuestro tiempo"19. Este pórtico weberiano de lucha simbólica moderna permite enmarcar el conflicto que ha observado Gordon Lynch $(2012,54-86)$ en Irlanda del Norte entre, por una parte, las formas sagradas dominantes que subyacen a la idea de nación católica irlandesa y, por otra parte, la sacralidad subyugada del cuidado de los niños que han experimentado abusos dentro de las escuelas católicas. A partir de 1921, justo después del Alzamiento de Pascua de 1916, la iglesia católica se convierte virtualmente en el proveedor exclusivo de cuidado residencial para los niños en el nuevo Estado irlandés. Las reglas fueron desplegadas al objeto de proporcionar un marco para el entorno educativo seguro que preparara a los niños para la vida adulta, sin embargo, en la práctica, los niños experimentaron a estas escuelas como lugares de abuso y abandono. A este sentimiento subjetivo visible en los niños se sumó en el 2006 el Report of the Ryan Commission to Inquire into the Child Abuse 20 que evidenció que el abuso y el abandono estaba tan extendido a través de las instituciones que tenía que ser entendido como un asunto sistémico, más profundo, que iba más allá de una serie de casos aislados. El Ryan Report pusó de manifiesto que las condiciones de abuso y abandono ocurrieron debido a decisiones estructurales más que a actos aislados de unos pocos individuos malévolos.

La primera forma sagrada está representada por la sacralidad otorgada a la nación católica irlandesa y ha tenido un carácter dominante. En los términos de un sacerdote republicano: "la República irlandesa no es solo el símbolo de nuestra independencia. Es algo cristiano y santo. Es el santuario donde surge el incienso sagrado de la devoción de Irlanda y de sus aspiraciones santas... Es el camino hacia ese destino que Dios tiene en mente para los niños de Gael" (P. Murray, 2000, 6-7; T. Brown, 2010, 26-27; C. C. O`Brian, 1994). Esta asociación del catolicismo con la resistencia cultural y política se pondrá de manifiesto en la adopción de nuevas prácticas devocionales en Irlanda tomadas de la Europa continental - incluyendo la adoración perpetua, las novenas, la devoción al sagrado Corazón, las peregrinaciones, las procesiones y los retiros monacales. Estas prácticas, junto con la expansión institucional en forma de iglesias, conventos, escuelas, orfanatos y hospitales, supuso una renovación de la vida cultural de los simbolos y sensibilidades católicas. Dentro de esta forma sagrada de la nación católica irlandesa, la sexualidad se convirtió en la piedra de toque de la pureza moral de la nación. La cohesión de ésta se basó en su pureza moral y esto es inseparable de la piedad católica y de las costumbres sexuales. Para mantener el prestigio de las escuelas como lugares de formación había que correr un tupido velo de silencio sobre los abusos.

Existen dos elementos que hacen posible la emergencia de la segunda forma sagrada, la sacralidad del cuidado de los niños, que ha subsistido históricamente como una forma sagrada dominada en Irlanda hasta tiempos muy recientes. El primero de ellos está representado por lo que Philippe Aries llama la "niñez larga" (1962, 329), esa fase de transición entre la infancia y la edad adulta, fase cuya existencia se despliega modernamente en occidente, a partir del siglo XIX (antes solo existía la "niñez corta") con el desarrollo de nuevas instituciones educacionales y con el desarrollo del Estado de Bienestar en el siglo XX. El segundo elemento hace referencia a la introducción de la discusión publica de la sexualidad y la emergencia del movimiento femenino en Irlanda a partir de los 60. La introducción de estos dos elementos pone fin al largo siglo XIX dentro de la sociedad irlandesa dominado por la sacralidad dominante de la nación católica irlandesa.

En el caso del País Vasco, asistimos igualmente a una conflicto entre las narrativas y rituales de resacralización de la nación y de la persona. Evidentemente, los contenidos de dichas formas sagradas cambian. Lo que el nacionalismo radical vasco posterior a Arana, padre fundador del nacionalismo vasco a finales del siglo XIX, sobre todo a partir de 1960, sacralizará como "pueblo de la nación", como quintaesencia de la identidad colectiva vasca, 
como algo construido, permanece para Arana ligado a un horizonte de sentido monoteísta. Los epígonos del aranismo proceden a sacralizar el núcleo del imaginario social central que legitimaba el mito nacionalista con su correspondiente historia o narrativa. En el lugar de Jaungoikoa (Dios) aparecerá Euskadi, o Euskalherria, es decir, el pueblo de la nación vasca será el macro-sujeto al cual quedarán referidas todas las ataduras primordiales que estaban anteriormente vinculadas a Dios. En su obra Nostalgia del Absoluto, George Steiner recurre a las expresiones: "credo sustitutorio" y "teología sustituta" para referirse a "sistemas de creencia y de razonamiento que pueden ser ferozmente antirreligiosos, que pueden postular un mundo sin Dios y negar la otra vida, pero, cuya estructura, aspiraciones y pretensiones respecto del creyente son profundamente religiosas en su estrategia y en sus efectos"21. ETA adoptará este planteamiento y lo hará realmente visible a través de las siglas que sirven para identificar al grupo nombrándolo: Euskadi ta Askatasu na: Pueblo Vasco y Libertad, Jaungoikoa ha sido substituido por Euskadi -marcando una diferencia con el discurso de Arana-, un pueblo todavia sometido al yugo de la invasión-manteniendo esta semejanza con el discurso de Arana. Cualquier medio será bueno con tal de acabar con el yugo de la colonización. El discurso de ETA es fundacionalista y fundamentalista. Hace tabula rasa de toda interpretación previa y se convierte en el nuevo profeta y guardián de una nueva identidad vasca renacida, reinventada, nuevamente. El problema no es que lo haga, esto hoy día resulta evidente, el problema radica en que lo hace monopolizando la representación de la identidad vasca por el recurso al terror y la violencia. Es decir, ETA hace suya esa moderna antimodernidad que procede también de la Revolución francesa y que se manifiesta en su vertiente jacobina, totalista, participatoria y totalitaria22. Esta racionalización política limitada que considera al "pueblo de la nación" como el portador indiscutible de la soberanía nacional subyuga las contingencias derivadas de una democracia deliberativa y la pluralidad de los actores potenciales a las demandas de un guión escrito por un sujeto político hipostasiado que actúa en nombre de un Ethnos, de una Muumbi, la nacionalista, pero que pretende representar a todas las otras Muumbis.

ETA adopta la violencia (desde su fundación ha asesinado a 829 personas) no sólo por razones de eficacia política sino también por su eficacia mágica, por su eficacia icono-política, pero esta eficacia icono-política comienza su declive cuando asesina, después de tenerlo secuestrado dos dias, al concejal del Partido Popular en Ermua, Vizcaya, Miguel Angel Blanco (MAB) de dos tiros en la nuca, con las manos atadas a la espalda. Este asesinato representa un key event (Caminos J. Ma ., Armentia J. I., Marín Flora, 2013, 140-160), un acontecimiento excepcional que desafia la posición dominante del discurso de la nación en el País Vasco para introducir una narrativa alternativa que procederá exitosamente a la resacralización de la persona, superando en eficacia icónica a los propios caídos de ETA. Este asesinato generará un rito piacular de duelo nacional, en donde se hará patente un gran proceso de movilización colectiva, de efervescencia colectiva, donde se pone de manifiesto que ETA ha atentado contra lo más sagrado, contra el corazón de la colectividad, la vida humana, generando un torrente de solidaridad que atraviesa las ideologías, las clases y los territorios. A partir de ese momento la legitimidad de la narrativa ritual violenta de la nación, apoyada en el terror, quedará totalmente destruida. La muerte de MAB no es otro asesinato más, es la condensación ritual de un trauma colectivo (J. C. Alexander, 2013) en el que comparecen la denuncia-rechazo, la energía emocional expresada y su dimensión estético-ritual (Birgitta Höijer, 2004, 522). Este acontecimiento apropiador golpea la conciencia colectiva, la unifica y deja una marca indeleble en la memoria colectiva. El acto supuso la creación de una imagen sagrada encarnada en el cuerpo ultrajado de un inocente a través de un intercambio entre la acción ritual llevada a cabo por la gente y la representación mediada de la narrativa visual de la muerte de MAB (Johanna Sumiala-Seppänen y Matteo Stochetti, 2005, 228-249, Ron Eyerman, 2011, 1-7)). 
Bibliografia

Alexander Jeffrey C., 2004, "On the Social Construction of Moral Universals: The 'Holocaust' from War Crime to Trauma Drama" in J. C. Alexander et alii, Cultural Trauma and Collective Identity, Berkeley, University of California Press, 196-264.

Alexander Jeffrey C., 2006a, "Cultural pragmatics: social performance between ritual and strategy" en J. C. Alexander, Bernhard Giese y Jason Mast (Editores), Social Performance. Symbolic action, Cultural Pragmatics and Ritual, Cambridge, Cambridge University Press, 2991.

Alexander Jeffrey C., 2006b, "From the Depth of Despair: performance, counterperformance and 'September 11"' en J. C. Alexander, Bernhard Giese y Jason Mast (Editores), Social Performance. Symbolic action, Cultural Pragmatics and Ritual, Cambridge, Cambridge University Press, 91-115.

Alexander Jeffrey C., 2010a, The Politics of Performance. Obama's Victory and the Democratic Struggle for Power, London, Oxford University Press.

Alexander J. C., (2010b), "Marxism and the Spirit of Socialism: Cultural Origins of Anticapitalism", Thesis Eleven, 100, 84-105.

Alexander Jeffrey C., 2013, Trauma. A Social Theory, Cambridge, Polity Press.

Alexander Jeffrey C. y Jaborsky Bernadette N., 2014, Obama Power, Cambridge, Polity Press.

Aries Philippe, 1962, Centuries of Chilhood. A Social History of Family Life, Nueva York, Vintage Books.

Asad Talal, 1993, Genealogies of Religion, Baltimore, Johns Hopkins University Press.

Asad Talal, 2003, The Formations of the Secular. Christiany, Islam and Modernity, Stanford, Stanford University Press.

Bellah R. N., 1970, Beyond Belief, Nueva York, Harper and Row.

Bellah R. N., 2005, "What is Axial about Axial Age?, European Journal of Sociology, 46, 69-89.

Bellah R. N. Tipton Steven M. (Editores), 2006, The Robert Bellah Reader, Durham, Duke University Press.

Bellah Robert N., 2007, "Religión civil en América" en Josetxo Beriain y Maya Aguiluz (Editores), Las contradicciones culturales de la modernidad, Barcelona, Anthropos, 114-139.

Bellah Robert N., 2011, Religion in the Human Evolution. From the Paleolithic to the Axial Age, Cambridge, Mass, The Belknap Press of the Harvard University.

Bellah R. N., Joas Hans ((Editores), 2012, The Axial Age and its Consequences, Cambridge, Mass, Harvard University Press.

Berger John, 1968, “The Nature of Mass Demonstrations”, New Society, No. 295, 23 May, 754755.

Berger P. L., 1967, The Sacred Canopy, Nueva York, Basic Books.

Brown Theodor, 2010, Ireland. A Social and Cultural History, 1922-2001 Londres, Harper Perennial. 
Caminos J. Ma ., Armentia J. I., Marín Flora, 2013, "El asesinato del Miguel Blanco como ejemplo de Key Event en el tratamiento mediático de los atentados mortales de ETA", Revista Estrategias, 6, 140-160.

Casanova José, 1997, "Globalizing Catholicism and the Return to a 'Universal' Church", en Suzanne Rudolph y James Piscatori (Editores), Transnational Religion and Fading States, Boulder, Westview Press.

Casanova José, 2002, "Beyond European and American Exceptionalisms: Towards a Global Perspective" en G. Davie, P. Hellas, L. Woodhead (Editores), Predicting Religion, Ashgate, Aldershot, 19-29.

Casanova José, 2006a, "Secularization Revisited: A Reply to Talal Asad" en David Scott y Charles Hirschkind (Editores), Powers of the Secular Modern, Stanford, Stanford University Press, 12-31.

Casanova José, 2006b, "Rethinking Secularization" The Hedgehog Review, Vol. 8, Nos 1 y 2, 723.

Casanova José, 2010a, "A Secular Age: Dawn or Twilight?" en Michael Warner, Jonathan van Antwerpen y Craig Calhoun (Editores), Varieties of Secularism in a Secular Age, Cambridge, Mass, Harvard University Press, 265-280.

Casanova José, 2010b, "Religion in Modernity as a Global Challenge" en J. Casanova, Hans Joas y otros, Religion und die umstrittene Moderne, Stuttgart, Kolhammer, 1-16.

Casanova José, 2011, "Cosmopolitanism, the Clash of Civilizations and the Multiple Modernities", Current Sociology, Vol. 59, 2, 252-267.

Collins Randall, 2004, Interaction Ritual Chains, Princeton, Princeton University Press.

Dalferth Ingolf U., 2012, "The Idea of Transcendence" en R. N. Bellah y H. Joas, (Editores), The Axial Age and its Consequences, Cambridge, Mass, Harvard University Press, 146-191.

Donald Merlin, 1991, The Origins of the Modern Mind. Three Stages in the Evolution of Culture and Cognition, Cambridge, Mass, Harvard University Press.

Durkheim Emile, 1899, "De la définition de les phénoménes religieux", L`Anne Sociologique, Vol. 2, 1-28.

Durkheim Emile, 1901-1902, "De quelques formes primitives de classification", L' Anne Sociologique, Vol. 6, 1-72.

Durkheim Emile, (1912), 1960, Les Formes elementaires de la vie religieuse. Le systéme totemique en Australie, París, Librairie Félix Alcan (Abreviado FE) (traducc española de Ramón Ramos en Akal, 1982).

Durkheim Emile, 1965, "La determinación del hecho moral" en Sociología y filosofia, Buenos Aires, Kraft.

Durkheim Emile, 1972, La educación moral, Buenos Aires, Shapire.

Durkheim E., 1973, "Individualism and the Intellectuals", Emile Durkheim on Morality and Society, (R. N. Bellah, ed.), Chicago, University of Chicago Press, 43-57.

Durkheim Emile, 1996a, "Sobre la definición de los fenómenos religiosos" Clasificaciones primitivas, Barcelona, Ariel, 105-139.

Durkheim Emile, Mauss Marcel, 1996b, "Sobre algunas formas primitivas de clasificación" en E. Durkheim, Clasificaciones Primitivas, Barcelona, Ariel, 23-105. 
Durkheim E., 2006, Lecciones de sociología. Física de las costumbres y del derecho, Granada, Editorial Comares.

Eisenstadt S. N., 1999, Fundamentalism, Sectarianism and Revolution. The Jacobin Dimension of Modernity, Cambridge, Cambridge University Press.

Eyerman Ron, 2011, The Cultural Sociology of Political Assassination. From MLK and RFK to Fortuyn and Van Gogh, Londres, Palgrave.

Filloux Jean-Claude, 1990, "Personne et sacré chez Durkheim" en Archives des sciences sociales des religions, $\mathrm{n}^{\circ} 69,41-53$.

Goffman Erwing, 1967, Interaction Ritual. Essays in Face-to-Face Behaviour, Pantheon Books, Nueva York.

Habermas Jürgen, 1987, Teoría de la acción comunicativa, Madrid, Taurus, Vol. 1.

Harrison Jane Ellen, 1912, Themis. A Study of the Social Origins of Greek Religion, Cambridge, Cambridge University Press.

Höijer Birgitta, 2004, "The Discourse of Global Compassion: The Audience and the Media of Human Suffering", Media, Culture and Society, Vol. 26, 4, 513-531.

Hunt Lynn, 1988, "The Sacred and the French Revolution" in Durkheimian Sociology: Cultural Studies, (Editor, Jeffrey C. Alexander), Cambridge, Cambridge University Press, 25-44.

Joas Hans, 2008, "Punishment and Respect: The Sacralization of the Person and its Endargement" en Jounal of Classical Sociology, Vol. 8, 2, 159-177.

Joas Hans, 2011, Die Sakralität der Person. Eine Neue Genealogie der Menschenrechte, Frankfort, Suhrkamp.

Joas Hans, 2012a, "A conversation with Robert Bellah" por, en The Hedgehog Review, Vol. 14, $\mathrm{n}^{\circ} 2,72-78$.

Kahn Paul W., 2007, Out of Eden. Adam and Eve and the Problem of Evil, Princeton, Princeton University Press.

Llobera J. R. 1994, The God of Modernity. The Development of Nationalism in Western Europe, London, Berg Publishers.

Lukes Steven, 1973, Emile Durkheim. His Life and Work: A Historical and Critical Study, Londres, Penguin.

Lukes Steven, 1975, "Political Ritual and Social Integration", Sociology, 9, 289-308.

Luhmann Niklas, 1977, “Transformation der Kontingenz im Sozialsystem der Religion” en Funktion der Religion, Frankfurt, Suhrkamp.

Lynch Gordon, 2012, The Sacred in the Modern World: A Cultural Sociological Approach, Oxford: OUP.

Mauss Marcel, 1979, "Sobre una categoría del espíritu humano: la noción de persona y la noción de “yo" en Sociología y antropología, Madrid, Tecnos, 309-336.

Mathiez Albert, (1904), Les origins des cultes revolutionaires (1789-1792), Paris, Societé Nouvelle des Editions.

Murray Peter, 2000, Oracles of God. The Roman Catholic Church and the Irish Politics, 1922, 1937, Dublin, UCD Press, 
Nocera Pablo, 2009, "Los usos del concepto de efervescencia y la dinámica de las representaciones colectivas en la sociologia durkheimiana", Revista Española de Investigaciones Sociológicas, (REIS), $\mathrm{n}^{\circ}$ 127, 93-119.

O`Brian Connor Cruise, 1994, Ancestral Voices. Religion and Nationalism in Ireland, Dublin, Poolberg Press.

Otto Rudolph, 1985, Lo santo. Lo racional y lo irracional en la idea de Dios, Madrid, Alianza.

Pickering W. S. F., 1984, Durkheim's Sociology of Religion. Themes and Theories, Londres, Routledge and Kegan Paul.

Rawls Anne Warfield, 2004, Epistemology and Practice. Durkheim's The Elementary Forms of Religious Life, Cambridge, Cambridge University Press.

Robertson-Smith William, 1889, Lectures on the Religion of The Semites. First Series: The Fundamental Institutions, Nueva York, Appleton and Company.

Sáez de la Fuente Inmaculada, 2002, El movimiento de liberación nacional vasco, una religión de sustitución, Bilbao, Desclee Brower.

Schmalenbach Herman, 1977, "Communion. A Sociological Category" (1922), en On Society and Experience, (Günther Lüschen y Gregory P. Stone, Editores), Chicago, The University of Chicago Press, 64-126.

Schütz Alfred y Luckmann Thomas, 1973, Las estructuras del mundo de la vida, Buenos Aires, Amorrortu.

Schütz Alfred y Luckmann Thomas, 1984, Strukturen der Lebenswelt, Francfort, Suhrkamp, Vol. II, 139-215.

Shils Edward y Young Michael, 1953, "The Meaning of the Coronation", Sociological Review, Vol. 1, 2, 63-81.

Shils Edward, 1975, Center and Periphery: Essays in Macro-Sociology, Chicago, University of Chicago Press.

Sieyes Enmanuel J., (1789), 1970, Qu'est ce que le Tiers Etat, Geneve, Droz.

Steiner George, 2001, Nostalgia del Absoluto, Madrid, Alianza.

Sumiala-Seppänen Johanna, Stochetti Matteo, 2005, "Mediated Sacralization and the Postmodern Constitution of Communio Sanctorum: The Case of the Foreign Swedish Minister Anna Lindl”, Material Religion, 1/2, 228-249.

Swedberg Rowald, 1994, "The Idea of "Europe" and the Origin of the European Union. A sociological Approach", Zeitschrift für Soziologie, 23, 5, 378-387.

Talmon Jacob, 1960, The Origins of Totalitarian Democracy, Nueva York, Praeger.

Taylor Charles, 1998, "Modes of Secularism" en Secularism and its Critics, Rajeev Bhargava (Editor), Oxford, Oxford University Press, 31-54.

Taylor Charles, 2007, A Secular Age, Cambridge, Mass, The Belknap of the Harvard University Press.

Tiryakian Edward, 1988, "From Durkheim to Managua: Revolutions as Religious Revivals" Durkheimian Sociology: Cultural Studies, (Editor: Jeffrey C. Alexander), Cambridge, Cambridge University Press, 44-66.

Tiryakian Edward, 1996, "Three Metacultures of Modernity: Christian, Gnostic and Chthonic", Theory, Culture and Society, Vol, 13, 1, 99-118. 
Tocqueville Alexis de, 1990, Democracy in America, Nueva York, Vintage.

Van der Veer Peter and Lehmann Harmut (Editors), 1999, Nation and Religion. Perspectives on Europe and Asia, Princeton, Princeton University Press.

Van der Veer Peter, 2001, Imperial Encounters: Religion Modernity in India and Britain, Princeton, Princeton University Press.

Warner W. Lloyd, 1959. The Living and the Dead: A Study of the Symbolic Life of Americans, New Haven, Yale University Press.

Warner W. Lloyd, 1962. American Life: Dream and Reality, Chicago, University of Chicago Press.

Weber Max, 1978, Economía y sociedad, México, D. F., FCE.

Weber Max, 1983, Ensayos sobre sociología de la religión, Madrid, Taurus, Vol. 1

Weber Max, 1988, Gesammelte Aufsätze zur Wissenschaftslehre, Tubinga, J. C. B. Mohr (Paul Siebeck).

\section{HOW TO CITE THIS ARTICLE IN BIBLIOGRAPHIES}

Beriain, Josetxo (2014): "Imaginarios postaxiales y resacralizaciones modernas". Revista Latina de Sociología, 4: 39-60, http://revistalatinadesociologia.com, ISSN 2253- 6469

\footnotetext{
1 Esta idea ha sido desarrollada por Peter van der Veer y Harmut Lehmann (Editores) en: Nation and Religion. Perspectives on Europe and Asia, 1999, 6.

2 Ver al respecto el trabajo de Peter van der Veer: "The Moral State: Religion, Nation and Empire" en Imperial Encounters: Religion and Modernity in India and Britain, 2001, 30 y ss.

3 Connor Cruise O`Brien en Ancestral Voices. Religion and Nationalism in Ireland, 1994, analiza el poema más nacionalista de William Butler Yeats, Cathleen ni Hoolihan, escrito en 1902 y que sirve de semilla al levantamiento irlandés de 1916.

${ }^{4}$ Habitualmente se considera que el hecho religioso está basado en el uso de conceptos binarios (sagrado/profano, trascendente/inmanente, religioso/secular y religioso/postsecular) que son utilizados como conceptos sinónimos cuando en realidad no lo son. Una genealogia afirmativa del significado diferenciado y de la génesis social de tales conceptos pone de manifiesto las metamorfosis del hecho religioso así como de sus representaciones conceptuales. El par sagrado/profano representa categorías epistemológico-cognitivas, comunes a toda experiencia religiosa, tanto en el tiempo como en el espacio, que separan diferentes dominios del mundo. Lo sagrado es un ámbito interdicto, separado y extraordinario frente a lo profano. Emile Durkheim, Rudolf Otto y Mircea Eliade, entre otros, han explorado estas categorías. El par "este mundo"/"el otro mundo" representa categorías históricas forjadas en torno al siglo V a C., dentro del surgimiento de la Edad Axial, cuyos portadores fundamentales son las "religiones universales" (World Religions). Cabe citar aquí, entre otras, las reflexiones de Max Weber, Karl Jaspers, S. N. Eisenstadt, Barry Schwartz y Robert Bellah. El par religioso/secular representa asimismo categorias históricas, pero esta vez nacidas en el seno del cristianismo europeo occidental. En él coexisten, por una parte, el dualismo existente entre "este mundo" (la Ciudad del Hombre) y "el otro mundo" (la Ciudad de Dios) y, por otra parte, el dualismo existente dentro de "este mundo" entre una esfera "secular" y otra "religiosa". Ernst Troeltsch, P. L. Berger, David L. Martin, Charles Taylor, José Casanova y Talal Asad, entre otros, han analizado estas categorias. El par religioso/postsecular representa categorias sociológicas nacidas dentro de un mundo ya "postsecular", en donde se ha producido un cuestionamiento del carácter evolucionista teleológico basado en estadios encarnado por la teoría de la secularización que surge del cristianismo europeo, así como una des-europeización del propio binomio religioso/secular, generando de esta guisa una constelación socioreligiosa nueva.

5 E. Durkheim, Vol. 2, 1899, 1-28, (citado en adelante por su traducción española incluida en E. Durkheim, Clasificaciones primitivas, Barcelona, Ariel, 1996a, 107).
} 
${ }^{6}$ Hans Joas, 2012a, Vol. 14, n ${ }^{\circ}$ 2, 75. Entrevista en donde Robert Bellah, ante preguntas muy bien dirigidas de Hans Joas, resume las idea-fuerza de su última gran obra: Religion in the Human Evolution. From the Paleolithic to the Axial Age, 2011

7 E. Durkheim, (En adelante citaré abreviadamente FE, por la cuarta edición francesa de PUF, 1960, y la edición española de Ramón Ramos de Akal,1982). FE, 308, 312-313/198, 205. Para una discusión interesante sobre la importancia del concepto de "efervescencia colectiva" en la sociología durkheimina y coextensivamente en el propio discurso sociológico, ver el trabajo de Pablo Nocera: "Los usos del concepto de efervescencia y la dinámica de las representaciones colectivas en la sociología durkheimiana”, 2009, 93-119.

8 E. Durkheim, FE, 312-13/205. Robert Bellah and Hans Joas, dos eminentes expertos en la obra de Durkheim, eligen este fragmento de los escritos de Durkheim para analizar el vinculo existente entre el ritual y la emergencia de la protodistinción, produciéndose de esta guisa una suerte de creatividad social emergente. Sus excelentes comentarios ilustran la profundidad del fragmento durkheimiano (R. N. Bellah, 2011, 17-18; Hans Joas, 1997, 93-94).

9 Las sociedades modernas no conforman una colectividad homogénea en sus creencias en la que sus miembros mantienen una única referencia simbólica, a la manera del modelo de integración social simple que Durkheim describe en las sociedades tribales, sino que existe un elenco múltiple de formas sagradas y seculares, debido a que "la creencia en Dios ya no es algo axiomático, (de que) hay alternativas" (Ch. Taylor, 2007, 3). Hemos pasado de una sociedad donde era virtualmente imposible no creer en Dios, o al menos no contar con el axioma de la creencia en Dios como eje cardinal del sentido común (porque estaba socialmente prescrito creer y proscrito el no creer, en un contexto masivamente creyente), a una donde la fe, incluso para el más radical de los creyentes, es una posibilidad (Ch. Taylor, 2007 , 3) humana entre otras. Charles Taylor, recogiendo la fórmula de Hugo Grotio, afirma que este hecho sociológico crucial producirá un nuevo patrón de significado según el cual actuamos dentro de un "marco inmanente secular" bajo la premisa: etsi Deus non daretur (Ch. Taylor, 1998, 34 y 36) ("como si Dios no existiera"), incluso si Dios no existiera, los principios que emanan de tal "mundo inmanente secular" son vinculantes. Se podria decir que en el seno del saeculum emerge una nueva distinción directriz, la que diferencia entre un "nosotros" (creyentes religiosos guiados por su fe, sea la que fuere) y el "ellos" (los sujetos postreligiosos que se rigen según pretensiones racionales de validez). Esto de ninguna manera significa que el ser humano haya dejado de ser religioso, sino más bien que determinadas cosas que pensamos o hacemos no tienen naturaleza religiosa ni precisan ser explicadas en términos religiosos o, en otras palabras, que se establece una geometria variable de opciones entre las esferas sagradas y las seculares. La diferenciación no solo existe dentro del propio hecho religioso sino que afecta a la diferenciación entre los hechos religiosos y los hechos seculares.

10 Albert Mathiez, en Los origenes de los cultos revolucionarios (1789-1792), en un trabajo citado por Durkheim en Las Formas Elementales..., ofrece una interesante descripción del nuevo culto, de sus lugares y de sus tempos más relevantes.

${ }^{11}$ La pauta ya la había marcado Robertson-Smith al afirmar que "la religión no existe para la salvación de las almas sino para la preservación y el bienestar de la sociedad" $(1889,30)$.

12 Según Shils $(1975,125)$, continuando la tradición durkheiminana, la gente precisa de algún orden sagrado en el centro de sus vidas al objeto de conducir la necesidad humana básica de integrarse en algo que trasciende y transfigura su existencia individual concreta.

${ }_{13}$ El fragmento está tomado de Tocqueville (1954, 310).

${ }_{14}$ Para un análisis del mundo profano como mundo de la vida ordinaria, de las rutinas habituales, ver el importante trabajo de Alfred Schütz y Thomas Luckmann: 1973. Sobre la génesis social de la trascendencia de los limites del mundo ordinario (y del propio self) y la creación de ámbitos extra-ordinarios, en donde es posible alcanzar tanto trascendencias de tipo no-religioso como trascendencias propiamente religiosas, ver asimismo el trabajo de Alfred Schütz y Thomas Luckmann (1984, Vol. II, 139-215). La capacidad de trascender lo dado es, probablemente, el equipamiento evolutivo más formidable con el que ha sido dotada la condición humana (Ver al respecto el excelente trabajo de Ingolf U. Dalferth $(2012,146-191)$.

15 H. Joas, 2008b, 8, 2, 159-177 y del mismo autor: Die Sakralität der Person: Eine neue Genealogie der Menschenrechte, 2011, 81-100. Joas asume y desarrolla el pionero estudio del tema de Jean-Claude Filloux: "Personee et sacré chez Durkheim", 1990, 41-53, así como el de Marcel Mauss: "Sobre una categoría del espíritu humano: la noción de persona y la noción de “yo”, 1979, 309-336.

16 Ver A. Comte: 1979, (1851-1854), Sistema...97.

17 Ver E. Durkheim: Las formas elementales de la vida religiosa, 1982, 398: "Los antiguos dioses envejecen o mueren, y todavía no han nacido otros (que los reemplacen)".

${ }_{18}$ M. Weber, Vol. 1, 1983, 441. Subrayados del propio Weber.

${ }^{19}$ M. Weber, 1975, 218. Subrayados míos.

20 Report of the Ryan Commission to Inquire into the Child Abuse, 2006, vol. V, capitulo 5, 26-27 (www.childabusecommission.ie/rpt/pdfs)

${ }_{21}$ G. Steiner, Nostalgia del Absoluto, Madrid, 2001, 16 y 19, citado en el libro de I. Sáez de la Fuente, El movimiento de liberación nacional vasco, una religión de sustitución, Bilbao, 2002, nota 8, página 62.

${ }_{22}$ Al respecto ver el clásico e imprescindible trabajo de Jacob Talmon: The Origins of Totalitarian Democracy, Nueva York, 1960 y el no menos imprescindible de S. N. Eisenstadt: Fundamentalism, Sectarianism and Revolution. The Jacobin Dimension of Modernity, Londres, 1999. 